\title{
Slow and fast development in ladybirds: occurrence, effects and significance
}

\author{
G. Mishra and Omkar \\ Ladybird Research Laboratory, Department of Zoology, University of Lucknow, Lucknow 226 007, India \\ Correspondence to: Omkar (omkaar55@hotmail.com)
}

Received: 12 December 2011 - Revised: 18 April 2012 - Accepted: 22 April 2012 - Published: 21 May 2012

\begin{abstract}
Developmental and growth rates are known to vary in response to genetic, developmental, physiological and environmental factors. However, developmental variations that exist within a cohort under any constant rearing condition are not so well investigated. A few such prominent polymorphisms have been studied, but not the subtle ones. The current study investigates the presence of such varying rates of development, slow and fast, in a cohort reared under constant conditions in two ladybirds, Cheilomenes sexmaculata and Propylea dissecta. Our results reveal slow and fast developers in the cohorts of each species and the ratio of slow and fast developers was similar. Slow developers showed a female biased sex ratio. The two developmental variants differed significantly in juvenile duration only in the first instar and the pupal stage, though variations in developmental time were observed in all stages. Fecundity was higher in slow developers, but developmental rates did not affect egg viability. The similar ratio in both ladybirds indicates it to be a result of either presence of a constant ratio across species or an effect of the similar rearing environment.
\end{abstract}

\section{Introduction}

Variations in environmental factors, such as diet, temperature, and photoperiod (Ernsting and Issaks, 2000; Davidowitz et al., 2004, 2005; Davidowitz and Nijhout, 2004; Plaistow et al., 2005) and the number of predators (Scriber, 2002; Röder et al., 2008; Chown and Gaston, 2010) are well known regulators of change in developmental rate. Such effects of environmental factors on development rate are well researched in a large number of organisms (e.g. Nylin and Gotthard, 1998; Gotthard, 2001; Davidowitz et al., 2004; Davidowitz and Nijhout, 2004; Stillwell et al., 2007, 2010; Chown and Gaston, 2010) with results indicating faster development under favourable and slower under unfavourable conditions.

These variations in developmental and growth rates are also considered responsible for the variation in sizes including that of the male being smaller than the female in ectothermic organisms (e.g. Teder and Tamaru, 2005; Blanckenhorn et al., 2007; Esperk et al., 2007; Stillwell et al., 2007, 2010). Fecundity selection is believed to be the driving force in the occurrence of female biased sexual size dimorphism in most of the insect orders (Hönek, 1993).
Other than these well recorded variations in developmental and growth rates, there exist a few which have been ignored. The faster development of a few individuals from an egg batch/cohort under a given rearing condition is an example of one such largely ignored variation. There have been a few studies addressing dramatic examples of this variation. In the myrmecophilous butterfly, Maculinea spp., about $25 \%$ of individuals from a cohort develop in one year and the rest in two years (Thomas et al., 1998; Schönrogge et al., 2000; Nowicki et al., 2005; Witek et al., 2006) with the former known as the annual morph, the latter as the biennial morph and the phenomenon as growth rate polymorphism. Similar incidences of growth rate polymorphism have also been reported in predaceous syrphid, Microdon mutabilis (Schönrogge et al., 2000) and salmonid fish (Gross, 1985). The bet hedging hypothesis discusses that some of the offpring of an individual will survive to reproduce as a result of a particular trait in question (Hanski, 1988; Hanski and Stahls, 1990; Thomas et al., 1998), which in the case of the present study is the probable polymorphic developmental trajectories. On the other hand, the slow growthhigh mortality hypothesis suggests that slow developers will 
be more in situations where mortality risks such as predatory or parasitic attacks are low since prolonged development increases the window of vulnerability (Benrey and Denno, 1997; Williams, 1999).

The above mentioned studies show instances of dramatic variations in developmental duration and rate. Their more subtle variations exist in almost all organisms, but have not been extensively investigated. In a study on lepidopteran, Manduca sexta, selection on the basis of these slight changes in larval growth rates, resulted in a $50 \%$ increase in pupal weight after 220 generations in $30 \mathrm{yr}$ (D'Amico et al., 2001).

Variations in developmental rates are also evident in ladybird beetles (Coleoptera: Coccinellidae), potential biocontrol agents of various insect pests (Hodek and Hönek, 1996; Dixon, 2000). These variations have been reported in response to temperatures (e.g. Semyanov, 2001; Omkar and Pervez, 2004; Pervez and Omkar, 2004; Nasution, 2007), prey quality (e.g. Kalaskar and Evans, 2001; Omkar and Srivastava, 2003; Kalushkov and Hodek, 2004; Michaud, 2005; Omkar and Mishra, 2005), prey quantity (Omkar and Pervez, 2003; Omkar et al., 2009), photoperiods and wavelengths (Hodek and Rủžička, 1979; Hodek and Iperti, 1983; Mishra and Omkar, 2005; Omkar et al., 2005) and sex (Hodek and Hönek, 1996; Dixon, 2000).

In addition to those discussed above, differences in developmental durations within a cohort under a given rearing condition have also been reported in ladybird beetles, Adalia bipunctata (Linnaeus) (Dixon, 2000), Harmonia axyridis (Pallas) (Grill et al., 1997) and Hippodamia convergens Guérin-Méneville (Rodriquez-Saona and Miller, 1995). In $H$. convergens, this variation has been used to isolate lines with shorter developmental time in order to facilitate their production for use in biocontrol (Rodriquez-Saona and Miller, 1995). After five generations, developmental time was reduced by $18 \%$, resulting in a $7 \%$ increase in intrinsic rate of population increase.

As the above mentioned literature suggests, the existence of such subtle developmental variants is usually informally observed but has not been formally acknowledged. The few studies that do acknowledge the presence of these slow-fast developmental variants and its exploitation for breeding purposes (Rodriquez-Saona and Miller, 1995; D'Amico et al., 2001) do not describe the developmental stage (s) at which the variation occurs. Further it is not known if it occurs at all developmental stages or is a continuous change or only at a particular stage.

Thus, the present study deals with the presence or absence of these variants within the selected cohort, the ratio of slow-fast developers, their sex ratio and the identification of immature stage(s) responsible for this variation, if any. For the purpose, two locally abundant ladybird species, Cheilomenes sexmaculata (Fabricius) and Propylea dissecta (Mulsant), were selected primarily owing to their fast development and prominent size variations. The study was conducted in two species so as to obtain check for consistency of patterns of these developmental variants. The results of this study should contribute to the identification of the presence of developmental rate polymorphism in ladybirds, if any, and can also be utilized for isolating lines for further assessment for use in biocontrol.

\section{Materials and methods}

\subsection{Ladybird beetles}

Propylea dissecta and C. sexmaculata are commonly occurring ladybirds found in almost all aphid colonies that infest agricultural and horticultural crops in and around Lucknow. Both these beetles are small ladybirds. Propylea dissecta has prominent sexual dimorphism in its pronotal pattern (Omkar and Pervez, 2000) which allows easy distinction between the two sexes thus making it a good model for reproductive studies. Both are generalist ladybirds with Aphis craccivora Koch being most suited for development and reproduction amongst a number of aphid species (Omkar and Bind, 2004; Omkar and Mishra, 2005).

\subsection{Stock maintenance}

The adults of ladybirds, $P$. dissecta and $C$. sexmaculata were collected from agricultural fields around Lucknow, India from infestations of A. craccivora on Dolichos lablab Linnaeus and Rhopalosiphum maidis (Fitch) on Zea mays Linnaeus, respectively. They were paired and placed in Petri dishes along with A. craccivora and observed for oviposition. The hatched neonates were reared in beakers on their respective prey, till adult emergence, which were then re-paired for continuation of the stock culture. Stocks were maintained under constant laboratory conditions $\left(27 \pm 2{ }^{\circ} \mathrm{C} ; 65 \pm 5 \% \mathrm{RH}\right.$; 12L:12D). Requisite stages for experiments were obtained from F2 generation of the stock culture.

\subsection{Experimental setup}

One hundred eggs of $C$. sexmaculata were taken from the same mother (12-day-old) over a period of 5 days. These were placed individually in plastic Petri dishes $(9.0 \times 2.0 \mathrm{~cm})$ and provided with daily replenished ad libitum supply of A. craccivora. They were observed every $12 \mathrm{~h}$ for mortality and moulting, and reared till adults emerged. The duration of each immature stage, survival and sex ratio of emerging adults were recorded. The emerging adults were separated and slotted as slow and fast developers on the basis of their total developmental period. This was done following frequency distribution graphs as described in the section on statistical analysis.

The newly emerged adults of each group, i.e. slow and fast developers, were paired for a lifetime and provided with ad libitum aphids (as mentioned above). The daily oviposition, 
egg viability and adult longevity was observed in 15 pairs from each group.

The above experiment was also conducted on $P$. dissecta (maintained on A. craccivora). For the purpose, 250 eggs randomly selected from 10 mothers from the stock were observed for immature development, survival and sex ratio of emerging adults. In this ladybird, the eggs belonged to different mothers and the setup thus allowed for preliminary assessment of maternal role, if any, in influencing slow and fast developers. Fecundity, egg viability and adult longevity were recorded in 50 pairs each of adults in both slow and fast developers.

\subsection{Statistical analysis}

Data on total developmental times of each species was subjected to Kolomogorov-Smirnov test of normality to assess for normal distribution. The total developmental times of C. sexmaculata $(D+=0.042, D-=0.040, D=0.042 ; P<$ $0.001 ; D$ being discrepancy statistics; it is an empirical distribution factor statistic which measures the discrepancy between a normal and a theoretical distribution, thereby testing for normality of data) and $P$. dissecta $(D+=0.084, D-=$ $0.074, D=0.084 ; P<0.01)$ were not normally distributed. The frequency data of the developmental times were then graphed to show distribution pattern, which was found to be bimodal (Fig. 1). Based on the graphical representation, data was divided into two groups, slow and fast developers, the means of which were then subjected to Student's t-test to confirm accuracy of grouping. Each developmental group was again subjected to Kolomogorov-Smirnov test of normality; but was found to be normally distributed and not sex influenced (C. sexmaculata: $D+=0.074, D-=0.072$, $D=0.074 ; P>0.15 ; P$. dissecta: $D+=0.068, D-=0.064$, $D=0.068 ; P>0.15)$. Graphical representation of frequency data of sex linked developmental times revealed lack of bimodal distribution.

$\chi^{2}$ analysis was used for comparison of data on number of slow and fast developers, number of females and males in each population, and immature survival in each species. Data were also subjected to General MANOVA with developmental durations of all immature stages, total developmental period and longevity as dependent variables and developmental group, sex and their interaction as independent factors followed by Tukey's post hoc comparison of means. The maternity of the cohorts was not included in the analysis as they belonged to different species, thereby not permitting clear separation of effects. Data on fecundity and percent egg viability were subjected to one-way ANOVA with developmental group as independent factor. MINITAB 15.0 was used for all the analysis.

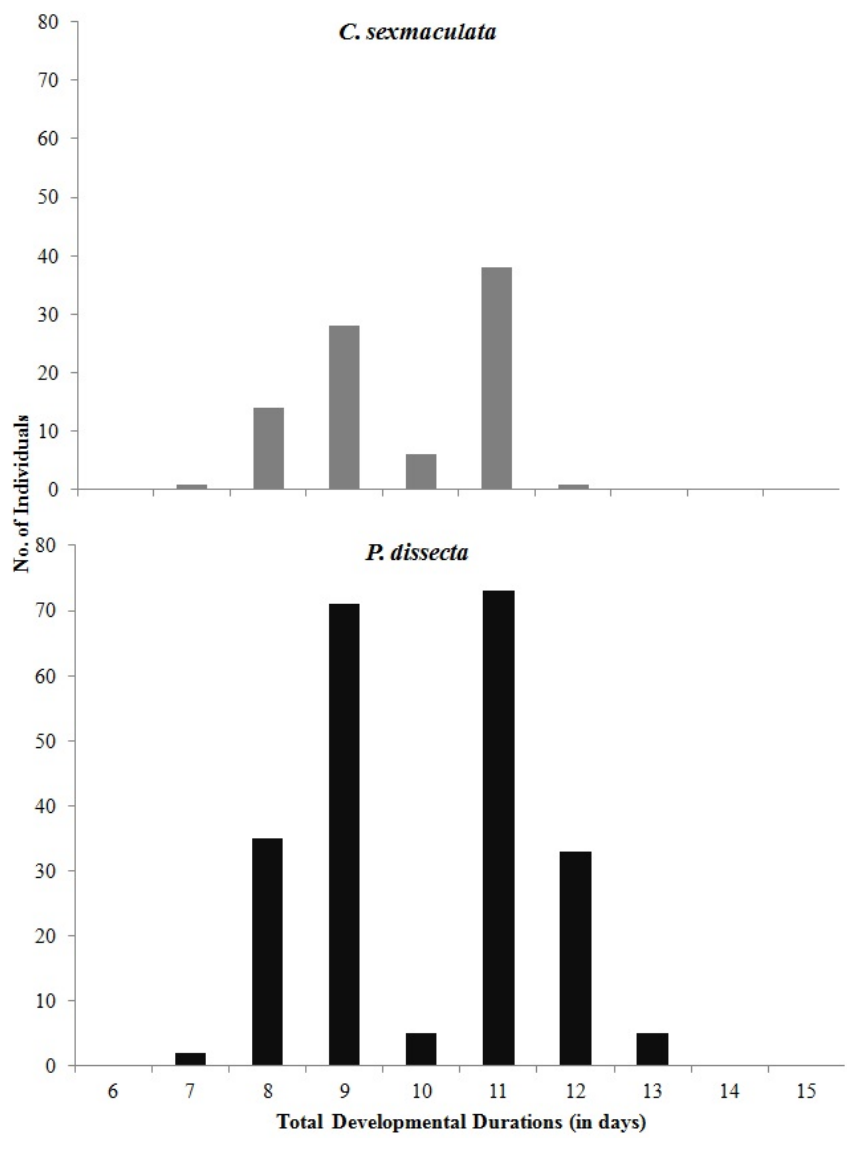

Figure 1. Frequency distribution of total developmental durations in ladybirds, C. sexmaculata and P. dissecta.

\section{Results}

Of the initial cohort of 100 in C. sexmaculata, only 88 reached maturity (survival $=88 \%$ ) and in these, almost equal numbers of slow (43) and fast (45) developers were recorded $\left(\chi^{2}=0.045 ; P=0.831 ; \mathrm{d} f=1\right)$. Similar was the case in $P$. dissecta with 229 of the initial cohort surviving (survival $=91.6 \%$ ), of which 113 were fast developers while 116 developed slowly $\left(\chi^{2}=0.039 ; P=0.843 ; \mathrm{d} f=1\right)$. Thus, under the given rearing conditions, the ratio of slow and fast developers was 0.4886 and 0.4936 in $C$. sexmaculata and $P$. dissecta, respectively, which was not significantly different $\left(\chi^{2}=0.036 ; P=0.899 ; \mathrm{d} f=1\right)$. Also, the percent immature survival did not differ significantly amongst the two ladybird species $\left(\chi^{2}=0.328 ; P=0.566 ; \mathrm{d} f=1\right)$.

The sex ratio was significantly female biased in slow developers of both the species, $C$. sexmaculata $\left(29+14{ }^{\wedge}=0.674 ; \chi^{2}=5.95 ; P=0.01 ; \mathrm{d} f=1\right)$ and $P$. dissecta $\left(81+35 \partial^{\lambda}=0.702 ; \quad \chi^{2}=18.24 ; \quad P=0.001 ; \quad \mathrm{d} f=1\right)$ but not in fast developers of $C$. sexmaculata (24: $\left.21 \hat{\widehat{o}}=0.533 ; \chi^{2}=0.56 ; P=0.454 ; \mathrm{d} f=1\right)$ and $P$. dissecta $\left(59+54{ }^{\lambda}=0.522 ; \chi^{2}=0.22 ; P=0.881 ; \mathrm{d} f=1\right)$. 
Table 1. Results of General MANOVA of certain life history traits of C. sexmaculata and P. dissecta.

\begin{tabular}{|c|c|c|c|c|c|}
\hline \multirow[t]{3}{*}{ Duration of Stage } & \multirow[t]{3}{*}{ Factors } & \multicolumn{4}{|c|}{ Species } \\
\hline & & \multicolumn{2}{|l|}{ P. dissecta } & \multicolumn{2}{|c|}{ C. sexmaculata } \\
\hline & & Wilk's statistic $(\mathrm{d} f)$ & $\begin{array}{l}F \text {-value } \\
\mathrm{P} \text {-value }\end{array}$ & Wilk's statistic $(\mathrm{d} f)$ & $\begin{array}{l}F \text {-value } \\
\mathrm{P} \text {-value }\end{array}$ \\
\hline \multirow[t]{3}{*}{ First Instar } & Developmental group & $0.64477(1.225)$ & $8.23^{2}$ & $0.72260(1.84)$ & $7.26^{2}$ \\
\hline & Sex & $0.88689(1.225)$ & $3.47^{1}$ & $0.79991(1.84)$ & $4.16^{1}$ \\
\hline & Sex $\times$ Developmental group & $0.89234(1.225)$ & $3.26^{1}$ & $0.78669(1.84)$ & $5.39^{2}$ \\
\hline \multirow[t]{3}{*}{ Second Instar } & Developmental group & $0.98136(1.225)$ & $2.01^{\mathrm{NS}}$ & $0.99123(1,84)$ & $1.15^{\mathrm{NS}}$ \\
\hline & Sex & $0.98791(1.225)$ & $1.26^{\mathrm{NS}}$ & $0.99102(1.84)$ & $1.09^{\mathrm{NS}}$ \\
\hline & Sex $\times$ Developmental group & $0.99907(1.225)$ & $0.91^{\mathrm{NS}}$ & $0.99119(1.84)$ & $1.11^{\mathrm{NS}}$ \\
\hline \multirow[t]{3}{*}{ Third Instar } & Developmental group & $0.99871(1.225)$ & $1.95^{\mathrm{NS}}$ & $0.99007(1.84)$ & $1.23^{\mathrm{NS}}$ \\
\hline & Sex & $0.99891(1.225)$ & $1.55^{\mathrm{NS}}$ & $0.99912(1.84)$ & $0.82^{\mathrm{NS}}$ \\
\hline & Sex $\times$ Developmental group & $0.97379(1.225)$ & $1.01^{\mathrm{NS}}$ & $0.99914(1.84)$ & $0.83^{\mathrm{NS}}$ \\
\hline \multirow[t]{3}{*}{ Fourth Instar } & Developmental group & $0.96894(1.225)$ & $2.12^{\mathrm{NS}}$ & $0.99119(1.84)$ & $1.11^{\mathrm{NS}}$ \\
\hline & Sex & $0.98635(1.225)$ & $1.26^{\mathrm{NS}}$ & $0.98786(1.84)$ & $1.31^{\mathrm{NS}}$ \\
\hline & Sex $\times$ Developmental group & $0.99367(1.225)$ & $0.82^{\mathrm{NS}}$ & $0.97405(1.84)$ & $0.77^{\mathrm{NS}}$ \\
\hline \multirow[t]{3}{*}{ Total Larval } & Developmental group & $0.81350(1.225)$ & $3.65^{*}$ & $0.79056(1.84)$ & $3.98^{1}$ \\
\hline & Sex & $0.80399(1.225)$ & $3.41^{1}$ & $0.79086(1.84)$ & $5.12^{2}$ \\
\hline & Sex $\times$ Developmental group & $0.90362(1.225)$ & $2.89^{1}$ & $0.88234(1.84)$ & $3.01^{1}$ \\
\hline \multirow[t]{3}{*}{ Prepupal } & Developmental group & $0.61340(1.225)$ & $9.36^{2}$ & $0.64591(1.84)$ & $8.01^{2}$ \\
\hline & Sex & $0.79356(1.225)$ & $4.58^{2}$ & $0.78162(1.84)$ & $6.23^{2}$ \\
\hline & Sex $\times$ Developmental group & $0.99165(1.225)$ & $2.02^{\mathrm{NS}}$ & $0.97379(1.84)$ & $1.01^{\mathrm{NS}}$ \\
\hline \multirow[t]{3}{*}{ Pupal } & Developmental group & $0.99910(1.225)$ & $1.73^{\mathrm{NS}}$ & $0.99862(1.84)$ & $2.22^{\mathrm{NS}}$ \\
\hline & Sex & $0.99236(1.225)$ & $0.98^{\mathrm{NS}}$ & $0.99001(1,84)$ & $1.19^{\mathrm{NS}}$ \\
\hline & Sex $\times$ Developmental group & $0.98012(1.225)$ & $1.08^{\mathrm{NS}}$ & $0.99962(1.84)$ & $0.63^{\mathrm{NS}}$ \\
\hline \multirow{3}{*}{$\begin{array}{l}\text { Total Developmental } \\
\text { Period }\end{array}$} & Developmental group & $0.59237(1.225)$ & $11.81^{2}$ & $0.44761(1.84)$ & $18.01^{2}$ \\
\hline & Sex & $0.78238(1.225)$ & $5.65^{2}$ & $0.81385(1.84)$ & $3.51^{1}$ \\
\hline & Sex $\times$ Developmental group & $0.98501(1.225)$ & $1.24^{\mathrm{NS}}$ & $0.99923(1.84)$ & $0.99^{\mathrm{NS}}$ \\
\hline \multirow[t]{3}{*}{ Adult Longevity } & Developmental group & $0.77134(1.225)$ & $6.64^{2}$ & $0.78920(1.84)$ & $5.61^{2}$ \\
\hline & Sex & $0.65236(1.225)$ & $8.65^{2}$ & $0.79823(1.84)$ & $4.21^{2}$ \\
\hline & Sex $\times$ Developmental group & $0.99876(1.225)$ & $2.05^{\mathrm{NS}}$ & $0.99802(1.84)$ & $1.99^{\mathrm{NS}}$ \\
\hline
\end{tabular}

${ }^{1}$ and ${ }^{2}$ indicate F-values to be significant at $P<0.05$ and $P<0.001$, respectively; NS indicates F-values to be non-significant at $P>0.05$; Data in parentheses are df-values.

The results also revealed that first instar, prepupal and total developmental durations differed significantly with developmental group and sex of the developing individuals (Table 1; Figs. 2 and 3). Tukey's post hoc comparisons of the developmental durations of fast and slowly developing immature stages within a species revealed that statistically significant differences in these durations were visible only during the first instar and the prepupal stage (Fig. 2). The total developmental periods in initial analysis had already been found to exhibit bimodal distribution. Such differences were also prominent between the two sexes within each species, with the males developing faster than the females (Figs. 2 and 3), however, these were not bimodally distributed. Comparison of interactions of the independent variables revealed that they were insignificant between sex and development group in all except for first larval instar (Table 1).

One-way ANOVA with developmental rate as independent factor and fecundity and egg viability as dependent ones revealed that higher numbers of eggs were laid by slow developers than those that had developed faster, while no significant differences were recorded in egg viability (Table 2). This trend was similar to both species.

\section{Discussion}

The results of this study indicate the presence of slow and fast developers in both the species of ladybirds. They were present in almost equal numbers in both species, with the female population being significantly more in the slow 


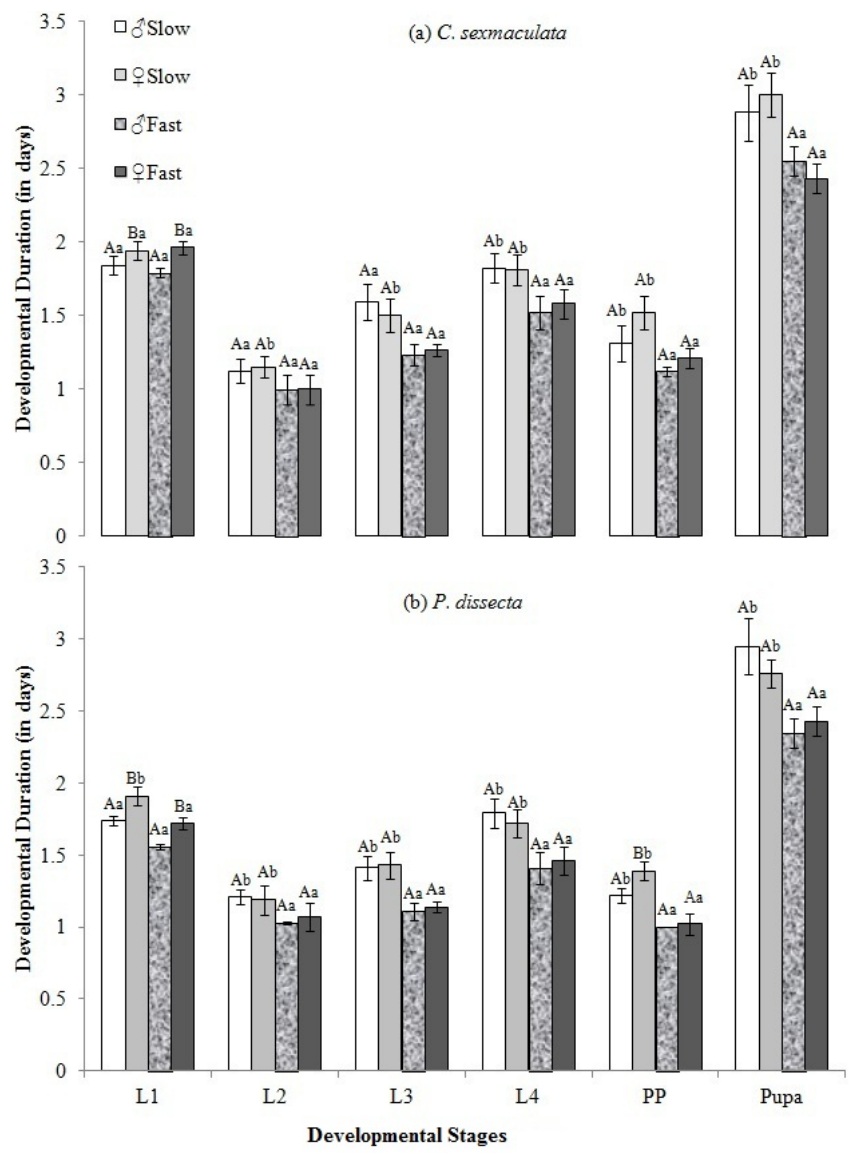

Figure 2. Durations of first (L1), second (L2), third (L3), fourth (L4) instars, prepupa (PP) and pupa in slow and fast developers of ladybirds $C$. sexmaculata and $P$. dissecta. Alphabets in upper case denote comparison between different sexes (male and female) of a developmental group (i.e. either slow or fast) within a species. Alphabets in lower case denote comparison between same sexes (either males or females) of the two different developmental groups (slow and fast) within a species. Similar numbers or alphabets denote lack of significance at $P>0.05$.

developers, while not so in fast developers. Also females that developed from slow developing larvae were more fecund than those developed from the fast developing ones. However, no such effect of developmental duration was observed on egg viability.

The consistency of the ratio of slow and fast developers in both the ladybirds indicates that it is likely to be constant across ladybird species but can only be confirmed through further studies. As per the slow growth-high mortality hypothesis, the number of fast developers in a population is likely to be higher in stressful situations. Numerous costs have been associated with accelerated growth in juvenile stages, (1) physiological, which compromise the ability to endure adverse environmental conditions (Sibly and Calow, 1986; Gotthard et al., 1994; Arendt, 1997; Gotthard, 2000, 2001), (2) developmental, indicating higher loss of viabil-

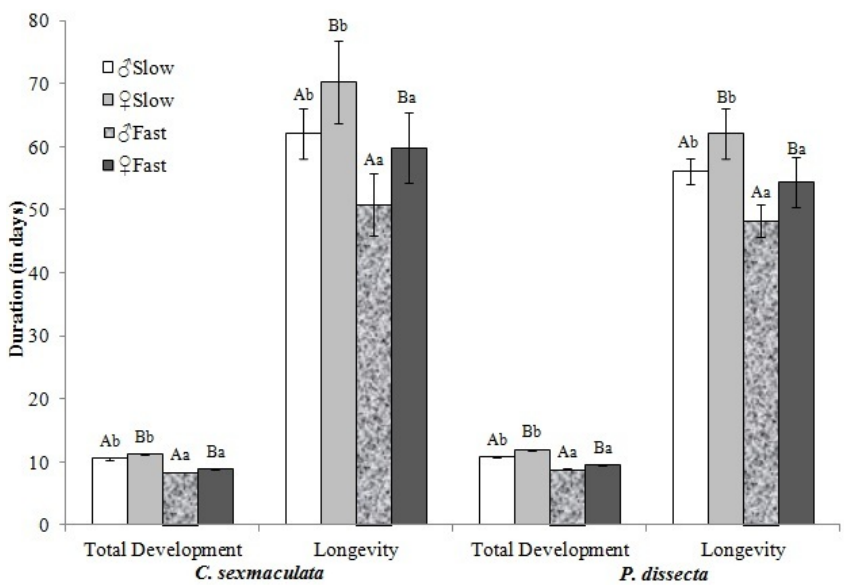

Figure 3. Total developmental duration and longevity of slow and fast developers in C. sexmaculata and P. dissecta. Alphabets in upper case denote comparison between different sexes (male and female) of a developmental group (i.e. either slow or fast) within a species. Alphabets in lower case denote comparison between same sexes (either males or females) of the two different developmental groups (slow and fast) within a species. Similar numbers or alphabets denote lack of significance at $P>0.05$.

ity due to structural or physiological errors (in Arendt, 1997; in Nylin and Gotthard, 1998), and (3) ecological, indicating higher foraging leading to increased predation risk (Lima and Dill, 1990; Anholt and Werner, 1998; Gotthard, 2000). On the other hand, slow development while causing increase in size and improving adult fitness, especially in females, may also cause early death because of the increased window of vulnerability (Roff, 1992; Stearns, 1992; Berger et al., 2006; Relyea, 2007). Gotthard (2001) discusses through his proposed model ( $S_{\text {juv }}=s^{t} ; S^{\text {juv }}=$ chance of juvenile to survive to reproduction, $s=$ daily survival chance, and $t=$ juvenile period in days) that the costs of growing fast might be less important than the costs for growing for a long time.

In view of (1) above listed costs of both slow and fast development, (2) the likelihood of more fast developers in a stressful rearing environment, and (3) the consistence of ratio across the two ladybird species, it can possibly be inferred that the current rearing environment was an equitable one favouring neither of the two developmental rates. The absence of predators, the individual rearing, the adequate supply of food and optimum temperature, humidity and photoperiod (Hodek and Hönek, 1996) are probably responsible for the current result. This ratio of slow and fast developers needs to be tested under varying stressful conditions for consistence. What also needs to be tested is whether the ratio is heritable or variable. Does it persist across generations or does it vary with the prevailing environmental conditions? How far is it affected by genes and environment? Is it affected by maternal or paternal lines? These are some of the many questions that need to be addressed not only for 
Table 2. Comparison of means of life history attributes of C. sexmaculata and P. dissecta.

\begin{tabular}{llll}
\hline Species & Developmental group & Fecundity (no. of eggs) & Egg viability (\%) \\
\hline C. sexmaculata & Slow & $836.54 \pm 69.98^{\mathrm{b}}$ & $89.20 \pm 7.36^{\mathrm{a}}$ \\
& Fast & $641.27 \pm 86.62^{\mathrm{a}}$ & $85.75 \pm 9.12^{\mathrm{a}}$ \\
& F-value & $23.31^{*}$ & $2.01^{\mathrm{NS}}$ \\
\hline P. dissecta & Slow & $996.78 \pm 32.26^{\mathrm{b}}$ & $87.32 \pm 5.01^{\mathrm{a}}$ \\
& Fast & $785.55 \pm 47.59^{\mathrm{a}}$ & $84.98 \pm 6.01^{\mathrm{a}}$ \\
& F-value & $12.06^{*}$ & $1.75^{\mathrm{NS}}$ \\
\hline
\end{tabular}

Values are Mean $\pm \mathrm{SE} ;{ }^{*}$ indicates F-values to be significant at $P<0.001$, respectively; NS indicates F-values to be non-significant at $P>0.05$; Values followed by similar alphabets denote lack of significance at $P>0.05$.

Comparison of means is only within species.

obtaining an ecological and evolutionary perspective but in the case of beneficial agents for purifying lines and improving performance as has been done in the case of $H$. convergens (Rodriguez-Saona and Miller, 1995).

The female biased sex ratio in the slow developers observed here could be due to higher male mortality in the larval stage. This could possibly be a result of males being primed for faster development (Stillwell et al., 2010).

The only significant difference in immature developmental durations of slow and fast developers was found in the first instar and pre-pupal stage. Such points of significant differences in developmental rates have earlier been observed in the later larval stages in stayrine butterflies (Wickman et al., 1990), and specifically in third larval instar in Pararge aegeria under different photoperiods (Gotthard, 2000). However, these results need to be carefully subjected to further experimentation as data also clearly reveals that the differences in slow and fast developers were visible in the ontogeny and the pattern was quite similar for all juvenile stages, indicating that these differences do not arise suddenly. Also between the two sexes, the difference in male and female maturation has been recorded both in the larval (albeit not a particular stage specifically) and pupal stages in butterflies (Wiklund et al., 1991). In ladybird beetles, social feeding is observed at the first instar stage (Hemptinne et al., 2000) and thus, group rearing of larvae is likely to improve their development and survival (Ito et al., 1982; Hemptinne et al., 2000). The isolated rearing of larvae in the present study could also have led to the prominent deviations observed in duration of first instar. Study of slow and fast developers in groups might shed more light on whether variation in first instar duration is an artifact of experimental design or an actual physiological deviation accounting for difference in development rates.

Also, as observed in the present study, females of slow developing larvae laid more number of eggs than those that developed from the fast developing ones. The effect on fecundity could also have been mediated through the effect of size (Stewart et al., 1991), a factor which we did not measure, and is thus a shortcoming of the present study.

Yet another interesting find is that despite different maternal ancestries, i.e. similar as well as varied in $C$. sexmaculata and $P$. dissecta, respectively, there was no difference in the developmental as well as reproductive trends observed in this study, indicating an absence of maternal effects. However, this is too preliminary a statement and should be subjected to rigourous experimentation prior to drawing firm conclusions.

The results of the present study raise more questions than it answers. What is revealed is that there exist both slow and fast developers in a population being reared under constant environmental conditions. Also the slow developers have significantly more females than males. There is a need for further rigourous experimentation in this nascent field on the lines of question raised in the discussion. The differences depicted above in the developmental rates could also be of much importance for economical exploitation in beneficial insects.

Acknowledgements. Authors are thankful to the Department of Higher Education, Govt. of Uttar Pradesh, Lucknow, India for financial support under Centre of Excellence programme.

\section{Declaration of authorship:}

We hereby declare that we have been personally involved in the design, conduct and reporting of new research and are fully responsible for the text. Principles of authorship have been followed.

Edited by: M. Foellmer

Reviewed by: S. Bjornson and two other anonymous referees

\section{References}

Anholt, B. R. and Werner, E. E.: Predictable changes in predation mortality as a consequence of changes in food availability and predation risk, Evol. Ecol., 12, 729-738, 1998.

Arendt, J. D.: Adaptive intrinsic growth rates: An integration across taxa, Q. Rev. Biol., 72, 149-177, 1997.

Benrey, B. and Denno, R. F.: The slow-growth-high-mortality hypothesis: a test using the cabbage butterfly, Ecology, 78, 987999, 1997.

Berger, D., Walters, R. E., and Gotthard, K.: What keeps insects small? - Size dependent predation on two species of butterfly larvae, Evol. Ecol., 20, 575-589, 2006. 
Blanckenhorn, W. U., Dixon, A. F. G., Fairbairn, D. J., Foellmer, M. W., Gilbert, P., van der Linde, K., Meier, R., Nylin, S., Pitnick, S., Schoff, C., Signorelli, M., Teder, T., and Wiklund, C.: Proximate causes of Rensch's rule: Does sexual size dimorphism in arthropods result from sex differences in development time?, Am. Nat., 169, 245-257, 2007.

Chown, S. L. and Gaston, K. J.: Body size variation in insects: a macroecological perspective, Biol. Rev., 85, 139-169, 2010.

D'Amico, L. J., Davidowitz, G., and Nijhout, H. F.: The developmental and physiological basis of body size evolution in an insect, Proc. R. Soc. Lond. B, 268, 1589-1593, 2001.

Davidowitz, G. and Nijhout, H. F.: The physiological basis of reaction norms: the interaction among growth rate, the duration of growth and body size, Integr. Comp. Biol., 44, 443-449, 2004.

Davidowitz, G., D'Amico, L. J., and Nijhout, H. F.: The effects of environmental variation on a mechanism that controls insect body size, Evol. Ecol. Res., 6, 49-62, 2004.

Davidowitz, G., Roff, D. A., and Nijhout, H. F.: A physiological perspective on the response of body size and development time to simultaneous directional selection, Integr. Comp. Biol., 45, 525$531,2005$.

Dixon, A. F. G.: Insect Predator-Prey Dynamics, Ladybird Beetles and Biological Control, Cambridge Univ. Press, p. 257, 2000.

Ernsting, G. and Isaaks, J. A.: Ectotherms, temperature, and tradeoffs: size and number of eggs in a carabid beetle, Am. Nat., 155, 804-813, 2000.

Esperk, T., Tammaru, T., Nylin, S., and Teder, T.: Achieving high sexual size dimorphism in insects: females add instars, Ecol. Entomol., 32, 243-256, 2007.

Gotthard, K.: Increased risk of predation as a cost of high growth rate: an experimental test in a butterfly, J. Anim. Ecol., 69, 896902, 2000

Gotthard, K.: Growth strategies of ectothermic animals in temperate environments, in: Animal Developmental Ecology, edited by: Atkinson, D. and Thorndyke, M., BIOS Scientific Publishers Ltd, Oxford, 2001.

Gotthard, K., Nylin, S., and Wiklund, C.: Adaptive variation in growth rate: life history costs and consequences in the speckled wood butterfly, Pararge aegeria, Oecologia, 99, 281-289, 1994.

Grill, C. P., Moore, A. J., and Brodie, E. D.: The genetics of phenotypic plasticity in a colonizing population of the ladybird beetles, Harmonia axyridis, Heredity, 78, 261-269, 1997.

Gross, M. R.: Disruptive selection for alternative life histories in salmon, Nature, 313, 47-48, 1985.

Hanski, I.: Four kinds of extra long diapause: a review of theory and observations, Ann. Ent. Fenn., 25, 37-53, 1988.

Hanski, I. and Stahls, G.: Prolonged diapause in fungivorous $\mathrm{Pe}$ gomya flies, Ecol. Entomol., 15, 241-244, 1990.

Hemptinne, J. L., Gaudin, M., Dixon, A. F. G., and Lognay, J.: Social feeding in ladybird beetles: adaptive significance and mechanism, Chemoecology, 10, 149-152, 2000.

Hodek, I. and Hönek, A.: Ecology of Coccinellidae, Kluwer Academic Publishers Dordrecht Boston London, 464 pp., 1996.

Hodek, I. and Iperti, G.: Sensitivity to photoperiod in relation to diapause in Semiadalia undecimnotata females, Ent. Exp. Appl., 34, 9-12, 1983.

Hodek, I. and Rủžička, Z.: Photoperiodic response in relation to diapause in Coccinella septempunctata (Coleoptera), Acta Entomol. Bohemoslov., 76, 209-218, 1979.
Hönek, A.: Intraspecific variation in body size and fecundity in insects: a general relationship, Oikos, 66, 483-492, 1993.

Ito, Y., Tsubaki, Y., and Osada, M.: Why do Leuhodrfia butterflies lay eggs in clusters?, Res. Pop. Ecol., 24, 375-387, 1982.

Kalaskar, A. and Evans, E. W.: Larval responses of aphidophagous ladybeetles (Coleoptera: Coccinellidae) to weevil larvae versus aphids as prey, Ann. Ent. Soc. Amer., 94, 76-81, 2001.

Kalushkov, P. and Hodek, I.: The effect of thirteen species of aphids on some life history life parameters of the ladybird Coccinella septempunctata, BioControl, 49, 21-32, 2004.

Lima, S. and Dill, L. M.: Behavioral decision made under the risk of predation: a review and prospectus, Can. J. Zool., 68, 619-640, 1990.

Michaud, J. P.: On the assessment of prey suitability in aphidophagous Coccinellidae, Eur. J. Entomol., 102, 385-390, 2005.

Mishra, G. and Omkar: Influence of components of light on the life attributes of an aphidophagous ladybird, Propylea dissecta (Coleoptera: Coccinellidae), Int. J. Trop. Insect Sci., 25, 32-38, 2005.

Nasution, L. M. D. H.: Maryani cyccu tobing dan darma bakti nasution, Biologi predator Cheilomenes sexmaculata (Fabr) (Coleoptera: Cocinellidae) pada kutu daun Macrosiphoniela sanborni Gilette (Homoptera: Aphididae), Agritrop, 26, 99-104, 2007.

Nowicki, P., Witek, M., Skorka, P., Settele, J., and Woyciechowski, M.: Population ecology of the endangered butterflies Maculinea teleius and $M$ nausithous, and its implications for conservation, Pop. Ecol., 47, 193-202, 2005.

Nylin, S. and Gotthard, K.: Plasticity in life-history traits, Annu. Rev. Entomol., 43, 63-83, 1998.

Omkar and Bind, R. B.: Prey quality dependent growth, development and reproduction of a biocontrol agent, Cheilomenes sexmaculata (Fabricius) (Coleoptera: Coccinellidae), Biocont. Sci. Tech. 14, 665-673, 2004.

Omkar and Mishra, G.: Preference-performance of a generalist predatory ladybird: a laboratory study, Biol. Cont., 34, 187-195, 2005.

Omkar and Pervez, A: Sexual dimorphism in Propylea dissecta (Mulsant), (Coccinellidae: Coleoptera), J. Aphidol., 14, 139$140,2000$.

Omkar and Pervez, A.: Influence of prey deprivation on biological attributes of pale morphs of the ladybeetle, Propylea dissecta (Mulsant), Insect Sci. Appl., 23, 143-148, 2003.

Omkar and Pervez, A.: Temperature-dependent development and immature survival of an aphidophagous ladybeetle, Propylea dissecta (Mulsant), J. Appl. Ent., 128, 510-514, 2004.

Omkar and Srivastava, S.: Influence of six aphid prey species on development and reproduction of a ladybird beetle, Coccinella septempunctata, BioControl, 48, 379-393, 2003.

Omkar, Mishra, G., and Singh, K.: Effect of different wavelengths of light on the life attributes of two aphidophagous ladybirds, Eur. J. Entomol., 102, 33-37, 2005.

Omkar, Kumar, G., and Sahu, J.: Performance of a predatory ladybird beetle, Anegleis cardoni (Weise) (Coleoptera: Coccinellidae) on three aphid species, Eur. J. Entomol., 106, 565-572, 2009.

Pervez, A. and Omkar: Temperature dependent life attributes of an aphidophagous ladybird beetle, Propylea dissecta (Mulsant), Biocont. Sci. Tech., 14, 587-594, 2004. 
Plaistow, S. J., Tsuchida, K., Tsubaki, Y., and Setsuda, K.: The effect of a seasonal time constraint on development time, body size, condition, and morph determination in the horned beetle Allomyrina dichotoma L (Coleoptera: Scarabaeidae), Ecol. Entomol., 30, 692-699, 2005.

Relyea, R. A.: Getting out alive: how predators affect the decision to metamorphose, Oecologia, 152, 389-400, 2007.

Röder, G., Rahier, M., and Naisbit, R. E.: Counterintuitive developmental plasticity induced by host quality, Proc. Royal Soc. London B, 275, 879-885, 2008.

Rodriquez-Saona, C. and Miller, J. C.: Life history traits in Hippodamia convergens (Coleoptera: Coccinellidae) after selection for fast development, Biol. Cont., 5, 389-396, 1995.

Roff, D. A.: The Evolution of Life Histories, Chapman and Hall, New York, 1992.

Schönrogge, K., Wardlaw, J. C., Thomas, J. A., and Elmes, G. W.: Polymorphic growth rates in myrmecophilous insects, Proc. Royal Soc. London B, 267, 771-777, 2000.

Scriber, J. M.: Latitudinal and local geographic mosaics in host plant preferences as shaped by thermal units and voltinism in Papilio spp (Lepidoptera), Eur. J. Entomol., 99, 225-239, 2002.

Semyanov, V. P.: The biology of coccinellids (Coleoptera, Coccinellidae) from South-East Asia III Lemnia biplagiata (Swartz), Entomol. Obozrenie, 80, 578-584, 2001.

Sibly, R. M. and Calow, P.: Physiological Ecology of Animals: an Evolutionary Approach, Blackwell Science, Oxford, 1986.

Stearns, S. C.: The Evolution of Life Histories, Oxford, Oxford University Press, 1992.
Stewart, L. A., Dixon, A. F. G., Ruzicka, Z., and Iperti, G.: Clutch and egg size in ladybird beetles, Entomophaga, 36, 329-333, 1991.

Stillwell, R. C., Morse, G. E. and Fox, C. W.: Geographic variation in body size and sexual size dimorphism of a seed-feeding beetle, Am. Nat., 170, 358-369, 2007.

Stillwell, R. C., Blanckenhorn, W. U., Teder, T., Davidowitz, G., and Fox, C. W.: Sex differences in phenotypic plasticity affect variation in sexual size dimorphism in insects: from physiology to evolution, Annu. Rev. Entomol., 55, 227-245, 2010.

Teder, T. and Tammaru, T.: Sexual size dimorphism within species increases with body size in insects, Oikos, 108, 321-334, 2005.

Thomas, J. A., Elmes, G. W., and Wardlaw, J. C.: Polymorphic growth in larvae of the butterfly Maculinea rebeli, a social parasite of Myrmica ant colonies, Proc. Royal Soc. London B, 265, 1895-1901, 1998.

Wickman, P. O., Wiklund, C., and Karlsson, B.: Comparative phenology of four satyrine butterflies inhabiting dry grasslands in Sweden, Holarctic Ecol., 13, 238-346, 1990.

Wiklund, C., Nylin, S., and Forsberg, J.: Sex-related variation in growth rate as a result of selection for large size and protandry in a bivoltine butterfly, Pieris napi, Oikos, 60, 241-250, 1991.

Williams, I. S.: Slow-growth, high-mortality - a general hypothesis or is it?, Ecol. Entomol., 24, 490-495, 1999.

Witek, M., Sliwinska, E. B., Skorka, P., Nowicki, P., Settele, J., and Woyciechowski, M.: Polymorphic growth in larvae of Maculinea butterflies, as an example of biennialism in myrmecophilous insects, Oecologia, 148, 729-733, 2006. 